\title{
Decision making with imperfect knowledge of the state space
}

Citation for published version (APA):

Mengel, F., Tsakas, E., \& Vostroknutov, A. (2011). Decision making with imperfect knowledge of the state space. METEOR, Maastricht University School of Business and Economics. METEOR Research Memorandum No. 013 https://doi.org/10.26481/umamet.2011013

Document status and date:

Published: 01/01/2011

DOI:

10.26481/umamet.2011013

Document Version:

Publisher's PDF, also known as Version of record

\section{Please check the document version of this publication:}

- A submitted manuscript is the version of the article upon submission and before peer-review. There can be important differences between the submitted version and the official published version of record.

People interested in the research are advised to contact the author for the final version of the publication, or visit the DOI to the publisher's website.

- The final author version and the galley proof are versions of the publication after peer review.

- The final published version features the final layout of the paper including the volume, issue and page numbers.

Link to publication

\footnotetext{
General rights rights.

- You may freely distribute the URL identifying the publication in the public portal. please follow below link for the End User Agreement:

www.umlib.nl/taverne-license

Take down policy

If you believe that this document breaches copyright please contact us at:

repository@maastrichtuniversity.nl

providing details and we will investigate your claim.
}

Copyright and moral rights for the publications made accessible in the public portal are retained by the authors and/or other copyright owners and it is a condition of accessing publications that users recognise and abide by the legal requirements associated with these

- Users may download and print one copy of any publication from the public portal for the purpose of private study or research.

- You may not further distribute the material or use it for any profit-making activity or commercial gain

If the publication is distributed under the terms of Article $25 \mathrm{fa}$ of the Dutch Copyright Act, indicated by the "Taverne" license above, 


\section{Maastricht University}

Friederike Mengel, Elias Tsakas,

Alexander Vostroknutov

Decision Making with I mperfect Knowledge of the State Space

$\mathrm{RM} / 11 / 013$

\section{METEOR}

Maastricht University School of Business and Economics

Maastricht Research School of Economics

of Technology and Organization

\section{P.O. Box 616}

NL - 6200 MD Maastricht

The Netherlands 


\title{
Decision Making with Imperfect Knowledge of the State Space*
}

\author{
Friederike Mengel Elias Tsakas Alexander Vostroknutov ${ }^{\dagger \ddagger}$
}

\author{
February 2011
}

\begin{abstract}
We conduct an experiment to study how imperfect knowledge of the state space affects subsequent choices under uncertainty with perfect knowledge of the state space. Participants in our experiment choose between a sure outcome and a lottery in 32 periods. All treatments are exactly identical in periods 17 to 32 but differ in periods 1 to 16 . In the early periods of the "Risk Treatment" there is perfect information about the lottery; in the "Ambiguity Treatment" participants perfectly know the outcome space but not the associated probabilities; in the "Unawareness Treatment" participants have imperfect knowledge about both outcomes and probabilities. All three treatments induce strong behavioural differences in periods 17 to 32. In particular participants who have been exposed to an environment with very imperfect knowledge of the state space subsequently choose lotteries with high (low) variance less (more) often compared to other participants. Estimating individual risk attitudes from choices in periods 17 to 32 we find that the distribution of risk attitude parameters across our treatments can be ranked in terms of first order stochastic dominance. Our results show how exposure to different degrees of uncertainty can have long-lasting effects on individuals' risk-taking behaviour.

JEL classification: D80, D81, C90

Keywords: risk preferences, ambiguity, awareness, experiments.
\end{abstract}

\footnotetext{
*We would like to thank Jayant Ganguli, Arno Riedl, the participants of the Experimental design seminar series at Maastricht University, and the participants of the seminar in Göteborg University for invaluable comments and help. All mistakes are ours.

†all authors: Department of Economics, Maastricht University, P.O. Box 616, Maastricht 6200 MD, The Netherlands. e-mail: f.mengel/e.tsakas/a.vostroknutov@maastrichtuniversity.nl

$\ddagger$ Contact author
} 


\section{Introduction}

Exposure to low probability or unexpected events can influence economic decision making and perception of risk in future seemingly unrelated domains. For example, Malmendier and Nagel (2010) show that experiencing macroeconomic shocks-like the Great Depression-in early life decreases the people's willingness to take financial risks in the long run, whereas experiencing an economic boom in the past increases future participation in the stock market. Nishiyama (2006) demonstrates that the Asian crisis of 1997 has resulted in a persistent increase in US banks' risk aversion. We experimentally investigate how unexpected or rare events influence future risk attitudes and how strong and long lasting these effects are.

In the literature on decision making under uncertainty, there are three standard distinct "types" of uncertainty, corresponding to different amounts of information about objective parameters of the lotteries. In a risky environment a decision maker knows all possible outcomes, as well as the associated probabilities. In an ambiguous environment the decision maker is typically assumed to know all possible outcomes but not the corresponding probabilities with which they occur (Ellsberg, 1961; Maccheroni, Marinacci, and Rustichini, 2006). Such "immeasurable" risk is also often referred to as Knightian uncertainty (Knight, 1921). In addition to not knowing the objective probabilities associated with each outcome the decision maker may be unaware of some possible outcomes, while at the same time knowing that he/she is not aware of the entire state space. Throughout the paper, we say that this decision problem is one with unawareness.

In this paper we study how such imperfect knowledge of the state space affects subsequent (unrelated) choices under uncertainty with perfect knowledge of the state space. In particular, participants in the computer lab are first given a sequence of choices between a fixed lottery and varying sure monetary outcomes (first task). There are three treatments that differ in the amount of information available about the lottery. In the Risk treatment participants see all outcomes of the lottery as well as their probabilities. In the Ambiguity treatment only outcomes are observed. In the Unawareness treatment participants see only some possible outcomes initially and no probabilities. Upon choosing the lottery they may become aware of additional outcomes. In each treatment participants are precisely explained which amount of 
information they do or do not have. This also means that in the Unawareness treatment they are "aware of their unawareness". After the first task, participants in all three treatments are given another sequence of choices between different lotteries and sure outcomes with all information available (second task).

Since in our experiment participants in the Unawareness treatment are aware of the fact that they do not know all outcomes this is in principle no different from ambiguity if one assumes that the decision maker deems "all" outcomes possible without knowing their probabilities. ${ }^{1}$ Since there are infinitely many possible outcomes in principle, we will refer to such environments as environments characterized by unawareness for the remainder of the paper. $^{2}$

Our main finding is that participants who have been exposed to an environment with very imperfect knowledge of the state space subsequently display different risktaking behaviour in standard decision making under risk. In particular, participants in the Unawareness treatment choose high variance lotteries significantly less often than participants in the ambiguity treatment who in turn choose these lotteries significantly less often than participants in the risk treatment. We conjecture that these spillovers are due to the fact that participants in the treatments with less information about the state space become more sensitive to the variance or risk associated with a lottery. Hence exposure to larger uncertainty in the first task makes participants react more to the uncertainty of each of the lotteries faced in the second task. We also find that, as expected, lotteries with higher expected value are chosen more often than those with lower expected value and lotteries with higher variance are generally chosen less often than those with lower variance irrespective of the treatment. We then estimate individual risk attitudes from choices in the second task and find that the distribution of risk attitude parameters across our treatments can be ranked in terms of first order stochastic dominance (FOSD). In particular the distribution of risk parameters in the Unawareness treatment dominates that of the Ambiguity treatment which in turn dominates that of the Risk treatment in terms of FOSD. These results demonstrate how exposure to different types of uncertainty-even in such a clinical environment as a laboratory experiment-can have long-lasting effects on individuals' risk-taking behaviour.

Our second finding is that the decision process in the first task of Unawareness

\footnotetext{
${ }^{1}$ Distinguishing probability zero events from unawareness is a topic which has attracted attention in theoretical research. See Feinberg (2009) for discussion.

${ }^{2}$ We will discuss this notion and related literature in more detail below. We will come back to this distinction when we present our results.
} 
treatment is qualitatively different from Risk and Ambiguity treatments. In particular, we find that participants in the Unawareness treatment react to surprise (revelation of new previously unknown lottery outcome) by choosing the sure outcome in the next period significantly more often. This reaction is the same irrespective of whether the surprise is positive or negative. We also find that participants in the Unawareness treatment react less to the size of the sure outcome and display quicker reaction times compared to the Risk and Ambiguity treatments which are not significantly different. This suggests that participants reaction to surprise is not a matter of simply updating a prior over the set of "all" possible outcomes, but rather a reaction to "unawareness." Participants seem to employ different decision heuristics in the first task of Unawareness treatment compared to the (first task of) Risk and Ambiguity treatments.

Previous research has demonstrated that individuals' decisions are affected by whether a choice situation displays only risk or whether it is ambiguous (Ellsberg, 1961; Halevy, 2007, among many others). In particular, it was found that people are ambiguity averse in a way which is inconsistent with subjective probability theories (Savage, 1954; Anscombe and Aumann, 1963). The focus of initial experimental studies was on refuting some of the axioms of subjective probability theories. Ahn et al. (2010) estimate parametric models of ambiguity aversion and risk aversion in portfolio-choice problems and find that-despite considerable heterogeneity-the majority of subjects are well described by subjective expected utility. Gollier (2009) also studies the relation between risk aversion and ambiguity aversion. These studies are quite different from our experiment in that we do not compare behaviour in risky/ambigous environments but rather investigate how having been exposed to such an environment affects risk attitudes in subsequent unrelated choices. Effects similar to ours have been documented in several empirical and field studies (Malmendier and Nagel, 2010; Nishiyama, 2006; Giuliano and Spilimbergo, 2009; Osili and Paulson, 2009). However, to our knowledge this is the first paper to generate a simple lottery choice environment in the laboratory which enables us to compare behaviour in risky/ambiguous situations and situations characterized by (awareness of) unawareness and isolate the persistent behavioural differences generated by each of these environments.

An additional novelty of our approach is to propose an experimental design to study (awareness of) unawareness. Unawareness has recently attracted quite a lot of attention among game theorists. It belongs to the broader literature on bounded rationality, and more specifically it is a special case of reasoning in the existence of unforeseen contingencies. One of the main reasons for the great focus that it has re- 
ceived, besides the obvious need to clarify its behavioral implications, is the fact that the first major contributions in this literature were two negative results which show that accommodating a notion of unawareness that satisfies some reasonable axioms is impossible both in a standard state space model (Dekel, Lipman, and Rustichini, 1998) and in a syntactic model (Modica and Rustichini, 1994). The proposed solution, in order to overcome the technical difficulties emerging from these results, was to make reasoning an awareness-dependent process (Fagin and Halpern, 1988; Modica and Rustichini, 1999; Heifetz, Meier, and Schipper, 2006; Li, 2009), i.e., the agents' language is restricted by the facts that they are aware of, and they can reason only within the bounds of their language. All the previous models share the common feature that agents are unaware of their own unawareness (AU-introspection). More recently, there have been attempts to extend this framework in a way that captures states of mind such that agents are aware of the possibility that they may be unaware of some fact (Halpern and Rêgo, 2008). This is the case that corresponds to our experiment, since-as mentioned before-participants in our experiment are aware of the fact that they may be unaware of some outcomes.

The paper is organized as follows. Section 2 gives the details of the experimental design. Section 3 describes the statistical tools and the mean variance utility model we estimate. In sections 4 and 5 we present the main results. Section 6 discusses the results. Appendix 7 contains instructions and further details of the experiment.

\section{Experimental Design}

In our experiment, participants are presented with 32 consecutive choices between lotteries and sure outcomes. There are 3 treatments called "Unawareness", "Ambiguity", and "Risk". The treatments differ only in the amount of information about the lotteries provided to the participants during the first 16 choices. The choices 17 to 32 are exactly identical across treatments.

In each period 1 to 16 participants choose between a fixed lottery and varying sure outcomes. The lottery is presented in Table 1.

\begin{tabular}{llllllll}
\hline Outcomes (Euro) & & & & & & & \\
& -20 & -1 & Twix & 6 & 8 & 10 & 14 \\
& 0.001 & 0.05 & 0.05 & 0.2 & 0.25 & 0.379 & 0.07 \\
Probabilities & & & & & & & \\
\hline
\end{tabular}

Table 1: The lottery from the first 16 choices. 
Notice that apart from the monetary outcomes the lottery also has an outcome called "Twix". A participant who chose the lottery and received the Twix outcome was given a real Twix chocolate bar at the end of the experiment. The idea behind the introduction of non-monetary outcome is to enlarge the space of outcomes that participants might consider. The sure outcomes in the first 16 choices varied from 5.4 Euro to 8.4 Euro with a 0.2 Euro interval and occurred in the same random order in all treatments. ${ }^{3}$

The treatments differ in the amount of information participants have about the lottery in Table 1. In the Risk treatment participants observe all outcomes and all probabilities as shown in Table 1. In the Ambiguity treatment participants know all outcomes but not the associated probabilities. In the Unawareness treatment participants see no probabilities and only some outcomes. In particular, from the first choice on the participants observe possible outcomes 6, 8, 10 and 14; in period 6 they are shown the possible outcome -1 ; in period 11 they are shown Twix; and in period 16 they are shown -20. If a participant chooses the lottery and an outcome is realized that she was previously unaware of (that she did not know previously) she is informed about it and the outcome will be displayed in all subsequent periods. In all treatments participants are informed about all those details in the Instructions, i.e. they know in the Ambiguity and Risk treatment that they know all outcomes and in the Unawareness treatment they are aware of the fact that they do not know all outcomes. ${ }^{4}$ Figures 1.abc show how the choices were presented to the participants.

In all treatments the choices in periods 17 to 32 are between a lottery with 2 outcomes and different sure amounts. These choices are the same across treatments. Participants observe both outcomes and probabilities of their occurrence (see Figure 1.d). The outcomes of the lotteries vary between 2 Euro and 20 Euro. The probabilities are chosen such that the expected values of all lotteries are in the interval between 7.94 Euro and 8.05 Euro. The sure outcomes vary between 6 and 8 Euro with a 0.5 Euro interval. ${ }^{5}$ All participants are informed that there are no other outcomes than those shown on the screen. They can also infer that since probabilities add up to one.

At the end of the experiment the participants were paid for one randomly chosen period in addition to a 4 Euro show-up fee. Overall, 104 participants have participated in the Risk treatment; 100 participants in the Ambiguity treatment; and 106

\footnotetext{
${ }^{3}$ See Section 7 for more details of the design.

${ }^{4}$ We ran the treatments in the order Unawareness, Ambiguity, Risk in order to avoid communication among participants regarding the information provided in different treatments.

${ }^{5}$ See Section 7.1 for the details.
} 


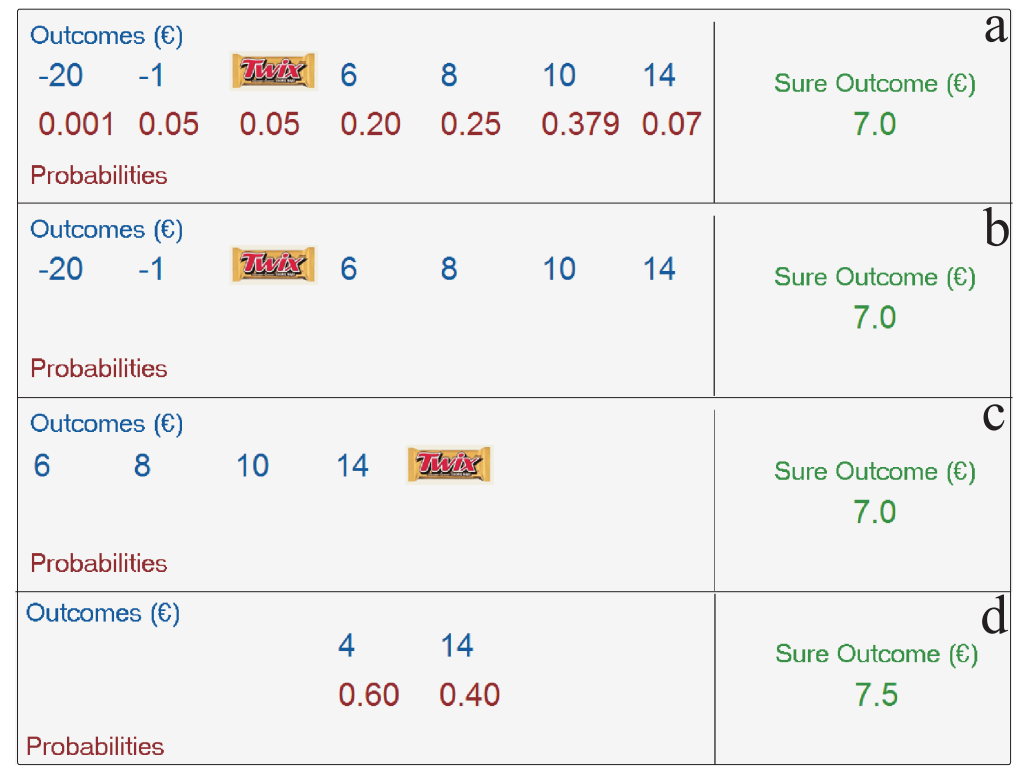

Figure 1: Screen shots of a typical choice in periods 1 to 16 in a) Risk treatment; b) Ambiguity treatment; c) Unawareness treatment: Screen of a participant who received a Twix some time before Period 6. d) a choice in periods 17 to 32 in all treatments.

participants in the Unawareness treatment. ${ }^{6}$ All experiments were run with z-Tree (Fischbacher, 2007) at Maastricht University in June - October 2010.

\section{Methods}

In order to estimate risk attitudes we use a mean-variance utility model (Markowitz, 1952). Utility of a lottery is assumed to be a weighted sum of its expected value and standard deviation. The positive coefficient on the expected value reflects the desire for higher monetary outcome and the negative coefficient on standard deviation reflects risk attitude. It is a well-known fact that mean-variance is consistent with the expected utility theory if and only if the utility function is quadratic. ${ }^{7}$ Some neuroeconomic evidence (e.g. Preuschoff, Bossaerts, and Quartz, 2006) even claims that

\footnotetext{
${ }^{6}$ We also conducted a control treatment where participants faced only the lotteries from periods 17 to 32. We will come back to this control treatment briefly in Section 8. The rest of our analysis will focus exclusively on the treatments discussed above. Other than the control treatment and the treatments discussed above we did not conduct any other treatments or pilots. We disregard the data from one session of the Unawareness treatment where there was a substantial program error.

${ }^{7}$ Tobin (1958) shows that the mean-variance model is consistent with the axioms of expected utility if the utility function is quadratic. Markowitz (1959) shows the converese, i.e., decisions based on MV can be reconciled with the axioms of EU only when the utility function is quadratic. For an overview, see Johnstone and Lindley (2011).
} 
mean-variance utility is encoded in the striatal regions of the brain.

Consider a lottery $\ell=\left(x_{1} \circ p_{1}, x_{2} \circ p_{2}, \ldots, x_{n} \circ p_{n}\right)$. We model utility as

$$
u(\ell)=K_{\theta}+\alpha_{\theta} E[\ell]-\beta_{\theta} S D[\ell]
$$

where $\alpha_{\theta}, \beta_{\theta}>0, K_{\theta}$ is a constant, $E[\ell]$ is expected value, $S D[\ell]$ is standard deviation and $\theta$ denotes the treatment (Risk, Ambiguity, Unawareness). ${ }^{8}$ For the degenerate lottery $(x)$ we have $u(x)=K_{\theta}+\alpha_{\theta} x$. Following (McFadden, 1976), we consider the random utility logit model which assumes that the probability of choosing the lottery $\ell$ over sure outcome $x$ is monotonic with respect to the difference of the utilities

$$
\alpha_{\theta} E[\ell]-\beta_{\theta} S D[\ell]-\alpha_{\theta} x=\alpha_{\theta}(E[\ell]-x)-\beta_{\theta} S D[\ell] .
$$

Thus, for the choices between lotteries $\ell_{t i}$ and sure outcomes $x_{t i}$ in period $t$ for participant $i$ we can use the random effects logit regression

$$
\operatorname{Prob}\left[\ell_{t i} \text { chosen }\right]=\Phi\left(E\left[\ell_{t i}\right]-x_{t i}, S D\left[\ell_{t i}\right], \ldots\right)
$$

to estimate $K_{\theta}, \alpha_{\theta}$ and $\beta_{\theta}$. In what follows the independent variable $E\left[\ell_{t i}\right]-x_{t i}$ will be called dexp and $S D\left[\ell_{t i}\right]$ will be called stdv.

Apart from the choices themselves we use response time, or the time it takes a participant to choose between lottery and sure outcome, in order to uncover more behavioral patterns. In general, longer response times reflect more information processing before the choice is made (e.g. Gneezy, Rustichini, and Vostroknutov, 2010) which is typically connected to the complexity of a decision problem. In case of the choice between two alternatives, the decision is easier the bigger is the gap between perceived utilities of the alternatives (Bogacz, 2007). Thus, response times can shed some light on the process by which participants make choices under the different informational regimes (Risk, Ambiguity and Unawareness).

\footnotetext{
${ }^{8}$ We use standard deviation instead of usual variance, because standard deviation is measured in the same units as expected value, which makes it easier to compare coefficients. There is also ample evidence in neuroeconomics literature in favor of the Temporal Difference (TD) learning model. In particular, many studies have found the encoding of the TD prediction error in the brain (e.g. O'Doherty et al., 2003). In case of a choice between two lotteries prediction error naturally translates into standard deviation (whereas variance corresponds to the squared prediction error). Finally (and non-surprisingly) our results are robust to using either standard deviation or variance.
} 


\section{Main Result}

In this section we analyze treatment differences in the behavior in periods 17 to 32 . As was mentioned above the choices that participants face in these periods are exactly the same in all three treatments. Therefore, any behavioral differences between treatments should be attributed to the experiences participants had in periods 1 to 16 . We hypothesize that experiencing different levels of knowledge about the state space in the first 16 periods differentially affects which aspects of the decision problem participants become more sensitive to. In particular, participants that have been exposed to a higher degree of uncertainty in periods 1 to 16 might be more sensitive to the uncertainty associated with the lottery in periods 17 to 32 .

\begin{tabular}{|c|c|c|c|c|c|}
\hline \multicolumn{6}{|c|}{ Pr(Lottery) } \\
\hline & (1) & (2) & (3) & (4) & (5) \\
\hline $\operatorname{dexp}$ & $\begin{array}{l}1.265^{* * *} \\
(0.107)\end{array}$ & $\begin{array}{l}1.252^{* * *} \\
(0.106)\end{array}$ & $\begin{array}{l}1.212^{* * *} \\
(0.063)\end{array}$ & $\begin{array}{l}1.218^{* * *} \\
(0.105)\end{array}$ & $\begin{array}{l}1.180^{* * *} \\
(0.062)\end{array}$ \\
\hline stdv & $\begin{array}{c}-0.325^{* * *} \\
(0.038)\end{array}$ & $\begin{array}{c}-0.322^{* * *} \\
(0.038)\end{array}$ & $\begin{array}{l}-0.320^{* * *} \\
(0.037)\end{array}$ & $\begin{array}{l}-0.312^{* * *} \\
(0.037)\end{array}$ & $\begin{array}{c}-0.311^{* * *} \\
(0.037)\end{array}$ \\
\hline per & $\begin{array}{l}-0.056^{* * *} \\
(0.014)\end{array}$ & $\begin{array}{l}-0.043^{* * *} \\
(0.008)\end{array}$ & $\begin{array}{l}-0.043^{* * *} \\
(0.008)\end{array}$ & & \\
\hline awar & $\begin{array}{l}0.859^{* *} \\
(0.384)\end{array}$ & $\begin{array}{l}1.093^{* * *} \\
(0.342)\end{array}$ & $\begin{array}{l}1.079 * * * \\
(0.328)\end{array}$ & $\begin{array}{l}1.073^{* * *} \\
(0.339)\end{array}$ & $\begin{array}{l}1.061^{* * *} \\
(0.324)\end{array}$ \\
\hline$a m b$ & $\begin{array}{l}0.513 \\
(0.387)\end{array}$ & $\begin{array}{l}0.629^{*} \\
(0.344)\end{array}$ & $\begin{array}{l}0.555^{*} \\
(0.328)\end{array}$ & $\begin{array}{l}0.621^{*} \\
(0.341)\end{array}$ & $\begin{array}{l}0.549^{*} \\
(0.325)\end{array}$ \\
\hline awar.stdv & $\begin{array}{c}-0.260^{* * *} \\
(0.056)\end{array}$ & $\begin{array}{c}-0.267^{* * *} \\
(0.056)\end{array}$ & $\begin{array}{c}-0.267^{* * *} \\
(0.055)\end{array}$ & $\begin{array}{c}-0.264^{* * *} \\
(0.055)\end{array}$ & $\begin{array}{c}-0.263^{* * * *} \\
(0.054)\end{array}$ \\
\hline$a m b \cdot s t d v$ & $\begin{array}{c}-0.149^{* * *} \\
(0.056)\end{array}$ & $\begin{array}{c}-0.152^{* * *} \\
(0.055)\end{array}$ & $\begin{array}{c}-0.158^{* * *} \\
(0.055)\end{array}$ & $\begin{array}{c}-0.151^{* * *} \\
(0.055)\end{array}$ & $\begin{array}{c}-0.156^{* * *} \\
(0.054)\end{array}$ \\
\hline awar.dexp & $\begin{array}{r}-0.038 \\
(0.151)\end{array}$ & $\begin{array}{r}-0.015 \\
(0.149)\end{array}$ & & $\begin{array}{r}-0.012 \\
(0.149)\end{array}$ & \\
\hline$a m b \cdot \operatorname{dexp}$ & $\begin{array}{r}-0.120 \\
(0.151)\end{array}$ & $\begin{array}{r}-0.107 \\
(0.150)\end{array}$ & & $\begin{array}{r}-0.105 \\
(0.149)\end{array}$ & \\
\hline awar.per & $\begin{array}{l}0.025 \\
(0.019)\end{array}$ & & & & \\
\hline amb.per & $\begin{array}{l}0.013 \\
(0.019)\end{array}$ & & & & \\
\hline const & $\begin{array}{l}1.294^{* * *} \\
(0.269)\end{array}$ & $\begin{array}{l}1.178^{* * *} \\
(0.248)\end{array}$ & $\begin{array}{l}1.207^{* * *} \\
(0.241)\end{array}$ & $\begin{array}{l}0.795^{* * *} \\
(0.236)\end{array}$ & $\begin{array}{l}0.822^{* * *} \\
(0.228)\end{array}$ \\
\hline$N$ & 310 & 310 & 310 & 310 & 310 \\
\hline
\end{tabular}

Table 2: Random effects panel data logit regression of choices between lotteries and sure outcomes in periods 17 to $32\left(^{*}-10 \%\right.$ significance; ${ }^{* *}-5 \%$; $\left.{ }^{* *}-1 \%\right)$. The numbers in parentheses are standard errors. The first 3 columns contain a period term and/or its interactions. 4960 observations, 310 independent.

Table 2 shows the random effects logit regression of choices in periods 17 to $32 .{ }^{9}$

\footnotetext{
${ }^{9}$ See Section 7.2 for the definitions of the independent variables and Section 7.1 for the exact payoffs
} 
Independent variables of interest are dexp - the difference between the expected value of the lottery and the sure outcome (ranging from -0.06 to 2.04 with an average of 0.99); stdv - the standard deviation of the lottery (ranging from 1.73 to 8.46 with an average of 4.54); per - the number of the period (normalized to range from 1 to 16); awar and amb - the dummies corresponding to the treatments; and interactions. ${ }^{10}$ As can be seen from columns (1) and (2) of Table 2 in all three treatments participants respond in the same way to the expected values of lotteries and sure outcomes: there are no treatment effects. Participants also show a slight tendency towards choosing the sure outcome as periods increase, but again there are no treatment differences (all coefficients awar.dexp, amb·dexp, awar.per and amb·per are insignificant). We included the variable per as well as interaction effects in regressions (1)-(3) to ensure that our variables dexp and stdv do not pick up time effects. In fact the correlation between per and $\operatorname{dexp}(\mathrm{stdv})$ is $\rho=0.1733^{* * *}(\rho=0.0044)$ respectively (Spearman correlation test). Regressions (4) and (5) show that our results are robust and quantitatively unchanged if we omit all period terms.

The most interesting effect though is the sensitivity to the standard deviation of the lotteries across treatments. We observe that the sensitivity to standard deviation is lowest in the Risk treatment (stdv), higher in the Ambiguity treatment $(s t d v+a m b \cdot s t d v)$, and highest in the Unawareness treatment (stdv + awar.stdv). In the Ambiguity treatment the regression coefficient for the standard deviation of the lottery is -0.478 with standard error 0.041 and $p<0.0001$. In the Unawareness treatment it is -0.587 with standard error 0.041 and $p<0.0001$ (column 3). The difference of coefficients between Unawareness and Ambiguity treatments is -0.109 with standard error 0.057 and $p<0.055$ (awar.stdv - amb·stdv). Participants show different sensitivity to standard deviations of the lotteries in periods 17 to 32 which are the same across all three treatments.

The dummy variables awar and amb have positive coefficients 1.079 and 0.555 respectively. This means that for the lotteries with standard deviations close to zero participants choose the lottery with the highest probability in the Unawareness treatment, lower probability in the Ambiguity treatment and the lowest probability in the Risk treatment. However, for the lotteries with high standard deviation ( $\operatorname{stdv}>5$ ) the situation is reversed. The model predicts that participants choose high standard deviation lotteries with the lowest probability in Unawareness treatment, higher prob-

used in each of the choices.

${ }^{10}$ See Section 3 for the explanations why these variables are used. 
ability in Ambiguity treatment and the highest probability in Risk treatment. ${ }^{11}$ This lends support to our conjecture that participants on average are more sensitive to the standard deviations of the lotteries in the Unawareness treatment, and less sensitive in Ambiguity and Risk treatments.

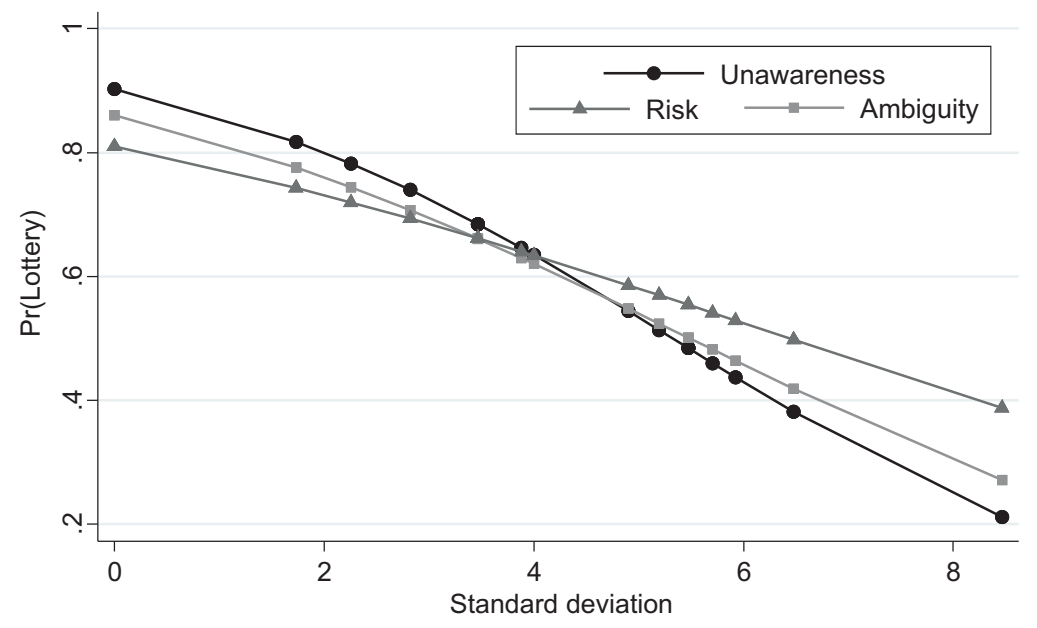

Figure 2: Predicted probabilities of choosing lottery as a function of its standard deviation in three treatments.

Figure 2 plots the probability with which a lottery was chosen in periods 17 to 32 as a function of the standard deviation of that lottery. As expected, lotteries with higher standard deviation are chosen less often reflecting risk aversion. Most interestingly, though, the order of treatments reverses as standard deviation increases. Lotteries with low standard deviation are chosen most often in the Unawareness treatment and least often in the risk treatment. For lotteries with high standard deviation this effect is exactly opposite - they are chosen most often in the risk treatment and least often in the Unawareness treatment. Interestingly all three treatments intersect at about the same point.

In terms of the mean-variance criterion $\alpha_{\theta}(E[\ell]-x)-\beta_{\theta} S D[\ell]$ our results (from Table 2) imply the following ranking of our treatments:

$$
\begin{aligned}
& \alpha_{\text {Unawareness }}=\alpha_{\text {Ambiguity }}=\alpha_{\text {Risk }} \\
& \beta_{\text {Unawareness }}>\beta_{\text {Ambiguity }}>\beta_{\text {Risk }} .
\end{aligned}
$$

Hence, while the participants' reaction to expected value in all treatments is the same, they react more strongly to variance in the Unawareness treatment than in the Ambiguity treatment and more strongly in the latter than in the Risk treatment. Keep

\footnotetext{
${ }^{11}$ In our data standard deviations range from 1.73 to 8.46.
} 
in mind that here we are talking about choices in periods 17 to 32 , i.e. about the spillover effect from having experienced choices in a risky/ambiguous environment or an environment characterized by "unawareness" on standard decision making under risk. In addition the last column of Table 2 shows that

$$
K_{\text {Unawareness }}>K_{\text {Ambiguity }}>K_{\text {Risk }}
$$

Taken together this evidence suggests that participants exposed to an environment characterized by "unawareness" start to focus much more on variance than other participants. They are less likely to choose lotteries characterized by high variance and more likely to choose lotteries characterized by very small variance.

Finally, we compare the distributions of individual risk attitudes in periods 17 to 32 in all three treatments. As was mentioned in Section 3 the weight $\beta$ on standard deviation in the mean-variance utility model can be thought of as an estimator of risk attitude. For each participant $i$ in our experiment we ran a logit regression

$$
\operatorname{Prob}\left[\ell_{t i} \text { chosen }\right]=\Phi\left(E\left[\ell_{t i}\right]-x_{t i}, S D\left[\ell_{t i}\right]\right)
$$

on 16 choices in periods 17 to 32 to estimate individual coefficient $\beta_{i}{ }^{12}$ Figure 3 shows the cumulative distributions of $\beta_{i}$ for the three treatments.

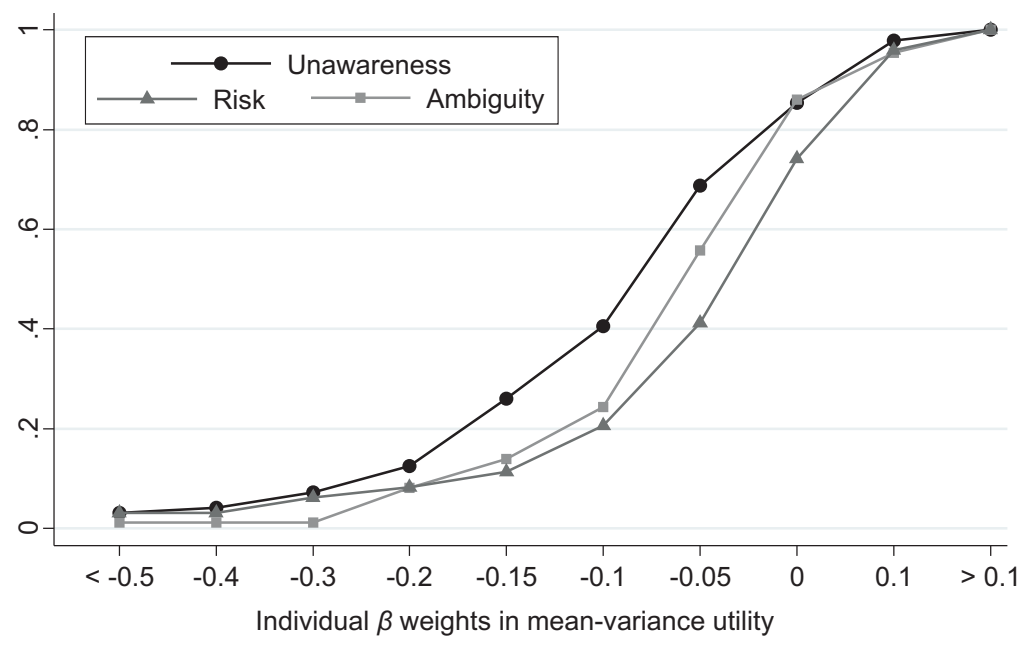

Figure 3: Cumulative distributions of individual $\beta$ weights (risk attitudes) in three treatments. $\beta=-0.3$ in the graph indicates a value of $\beta \in(-0.4,-0.3]$

Notice that cdf of risk attitudes in Unawareness treatment first-order stochasti-

\footnotetext{
${ }^{12}$ We dropped participants who always chose either lottery or sure outcome. In total there were 96 participants in the Unawareness treatment, 87 in ambiguity and 97 in the risk treatment.
} 
cally dominates cdf in Risk treatment. This implies that exposure to an environment with awareness of unawareness uniformly increases risk aversion (as measured by $\beta_{i}$ ) of all participants with any risk attitude. The cdf for Ambiguity treatment is in between the cdfs for the Unawareness and Risk treatments in terms of first order stochastic dominance in the steep part of the graph where most observations are. This provides further evidence for the lasting effects of exposure to environments with varying types of uncertainty on participants risk attitudes.

Result 1 1. Participants in the Unawareness treatment are more (less) likely to choose low (high) variance lotteries than participants in the Ambiguity treatment than participants in the Risk treatment, implying the following ranking of risk parameters $\beta$ on the population level: $\beta_{\text {Unawareness }}>\beta_{\text {Ambiguity }}>\beta_{\text {Risk }}$.

2. The distributions of individual risk attitude parameters across the three treatments are ranked as follows in terms of first-order stochastic dominance: $\beta_{\text {Unawareness }} \succ_{\text {FOSD }} \beta_{\text {Ambiguity }} \succ_{\text {FOSD }} \beta_{\text {Risk. }}$

\section{Periods 1 to 16}

\subsection{Choices}

For the choices in periods 1 to 16 we analyze behavior in the Unawareness treatment and in the Ambiguity/Risk treatments separately.

Unawareness Treatment. We will study how "surprise" (becoming aware of new possible outcomes) affects choices. Understanding whether and how participants react to what we have termed surprise will help us to gain some insight into whether we can reasonably assume that participants were unaware of outcomes -1 , Twix and -20 or whether they considered all outcomes possible treating the situation essentially as a decision problem under ambiguity.

Figure 4 shows the average choices of participants in the period immediately after they became aware of outcomes -1 or Twix. There are two ways in which participants in the Unawareness treatment can receive -1 or Twix: 1) a participant chooses the lottery and the previously unknown -1 or Twix is realized (it appears on participant's screen); 2) a participant chooses the lottery after period 6 (11) and receives -1 (Twix). In the latter case participants are already aware that -1 (Twix) can happen as possible outcome of the lottery since it is displayed on their screens after period 6 (11) regardless of their choices. Therefore, on average the only difference between the 


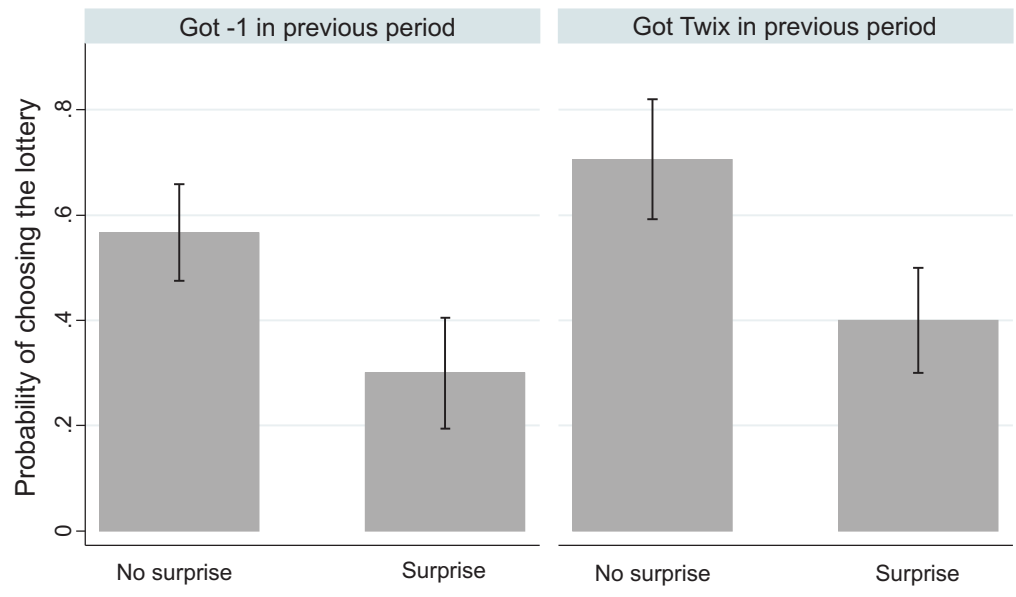

Figure 4: Probabilities of choosing the lottery in the first 16 periods in the Unawareness treatment after receiving payoff -1 or Twix by surprise.

choices in two cases is the presence/absence of surprise. As Figure 4 clearly indicates participants tend to choose the lottery significantly less often in the period following the surprise than in the period following the outcome that participants were aware of. This effect is strongly significant (Spearman test $p<0.0001$ ). In addition we can see from Table 3 that participants choose the lottery on average less often over time in the first 16 periods of the Unawareness treatment. Since the surprise always happens in earlier periods than the "no surprise" this effect is even probably underestimated in Figure 3. Note also that it is the mere unexpectedness of the outcome and not its value that generates this effect since Twix can be thought of as having some positive value to the participants.

Table 3 reports the logit regression of choices depending on the sure outcome; period; dummy firstsp that is equal to 1 in all periods including and after the one in which participant saw first previously unknown outcome (-1, Twix, or -20$)$; and their interaction. Obviously firstsp is strongly correlated with per by construction.

The table illustrates that participants react to the value of the sure outcome in the right direction: on average they choose sure outcome more often the bigger it is (sure). Also over time participants tend to choose the lottery less often in the unawareness treatment. Obviously the variable firstsp (which is distinct from surprise in Figure 4) is highly correlated with period and has a negative coefficient as well in the regression. Since in Figure 4 we have seen that participants tend to choose the lottery less often after they have been surprised we conjecture that the negative coefficient on period may at least partly be due to the fact that participants become more cautious over time because they have experienced "surprise" in the past. 


\begin{tabular}{|c|c|c|c|}
\hline \multicolumn{4}{|c|}{ Pr(lottery) } \\
\hline & $\beta /(s e)$ & $\beta /(s e)$ & $\beta /(s e)$ \\
\hline sure & $\begin{array}{c}-1.623^{* * *} \\
(0.226)\end{array}$ & $\begin{array}{l}-1.274^{* * *} \\
(0.085)\end{array}$ & $\begin{array}{c}-2.149^{* * *} \\
(0.198)\end{array}$ \\
\hline per & & $\begin{array}{l}-0.178^{* * *} \\
(0.015)\end{array}$ & $\begin{array}{c}-0.808^{* * * *} \\
(0.123)\end{array}$ \\
\hline firstsp & $\begin{array}{l}-6.576^{* * *} \\
(1.760)\end{array}$ & & \\
\hline per·sure & & & $\begin{array}{l}0.091^{\text {*** }} \\
(0.017)\end{array}$ \\
\hline firstsp.sure & $\begin{array}{l}0.623^{* * *} \\
(0.236)\end{array}$ & & \\
\hline const & $\begin{array}{c}13.796^{* * *} \\
(1.703)\end{array}$ & $\begin{array}{c}11.271^{* * * *} \\
(0.698)\end{array}$ & $\begin{array}{c}17.318^{* * * *} \\
(1.462)\end{array}$ \\
\hline$N$ & 106 & 106 & 106 \\
\hline
\end{tabular}

Table 3: Random effects logit regression of choices in the first 16 periods of the Unawareness treatment.

All Treatments. Next, we analyze the choices of participants in first 16 periods across all three treatments. Table 4 reports the logit regression of choices depending on sure outcome; dummies that indicate the treatment as well as interaction terms.

\begin{tabular}{lcc}
\hline \hline \multicolumn{3}{c}{ Pr(lottery) } \\
& \multicolumn{1}{c}{$\beta /(s e)$} & $\beta /(s e)$ \\
\hline Risk, Ambiguity, Unawarenes \\
& $-2.025^{* * *}$ & $-2.104^{* * *}$ \\
& $(0.113)$ & $(0.088)$ \\
awar & $-6.294^{* * *}$ & $-5.748^{* * *}$ \\
& $(0.996)$ & $(0.840)$ \\
amb & -0.761 & \\
& $(1.161)$ & \\
awar·sure & $0.979^{* * *}$ & $1.051^{* * *}$ \\
& $(0.134)$ & $(0.114)$ \\
amb·sure & -0.203 & \\
& $(0.164)$ & \\
const & $14.312^{* * *}$ & $13.821^{* * *}$ \\
& $(0.826)$ & $(0.621)$ \\
$N$ & 310 & 310 \\
\hline \hline
\end{tabular}

Table 4: Random effects logit regression of choices in the first 16 periods of Risk, Ambiguity and Unawareness treatments.

Important observation is that there are no apparent differences between Risk and Ambiguity treatment (amb and amb-sure are insignificant). This suggests that participants in these treatments make choices in similar fashion. However, choices in Unawareness treatment are very different. Here participants seem to be less sensitive 
to sure outcomes than in the Risk treatment (sure + awar-sure). Moreover, participants tend to choose sure outcome more often overall (awar). This suggests that participants may employ different decision heuristics in the Unawareness and Ambiguity/Risk treatments. One conjecture could be that in the Unawareness treatment the first occurrence of "surprise" triggers some simple decision heuristic that biases choices towards sure outcomes (compared to EU maximization).

\subsection{Response Times}

To shed some more light on the behavior in the Unawareness treatment we analyze response times of the participants in the first 16 periods. Figure 5 shows the response times in reaction to surprise. The data points presented on this graph are the same as on the analogous graph for choices (Figure 4).

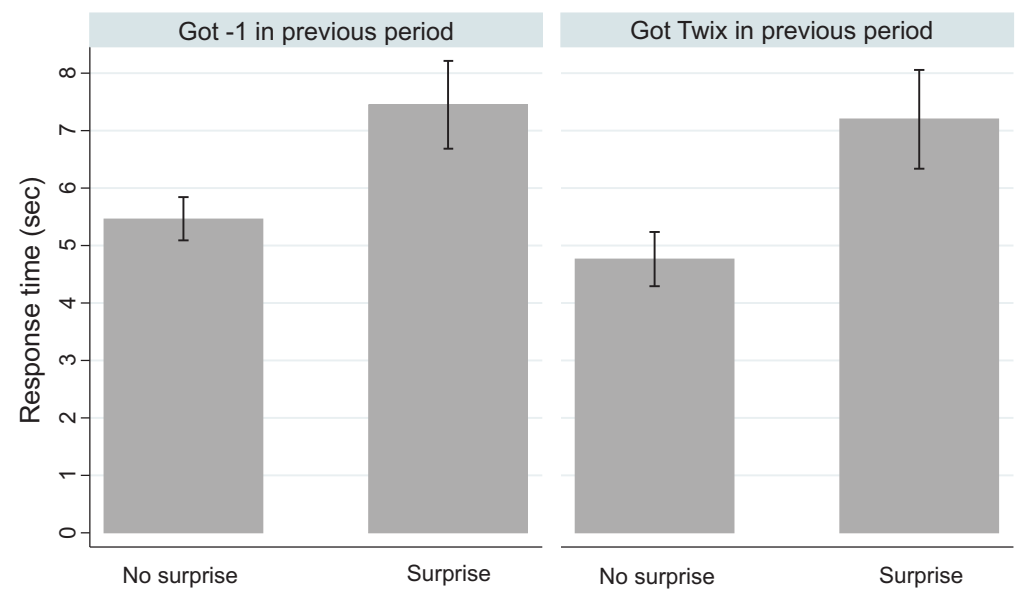

Figure 5: Response times in the first 16 periods in Unawareness treatment after receiving payoff -1 or Twix by surprise.

We see that in the period immediately following surprise the reaction time is significantly higher compared to periods following no surprise. This supports the view that participants were indeed "unaware" of the outcome previously.

To gain more insight into the nature of the decision process in the first 16 periods we now look at the response times across treatments. Table 5 shows that response time depends on the sure outcome in Risk and Ambiguity treatments in the right direction: the higher the sure outcome the faster is the decision. ${ }^{13}$ However, in Unawareness treatment response time does not react to the value of the sure outcome (sure + awar.sure is insignificant). Moreover, in Unawareness treatment there

\footnotetext{
${ }^{13}$ See Section 3 for possible theoretical explanation of this effect.
} 
is an overall drop in the response time comparing to Risk and Ambiguity treatments (awar). All this is consistent with the conjecture made in Subsection 5.1 that choice heuristic is different between Unawareness and Risk/Ambiguity treatments: in Unawareness treatment the decisions are faster and less dependent on the sure outcomes.

\begin{tabular}{lcc}
\hline \hline \multicolumn{3}{c}{ Response time } \\
& \multicolumn{1}{c}{$\beta /(\mathrm{se})$} & $\beta /(\mathrm{se})$ \\
\hline sure & $-0.421^{* * *}$ & $-0.450^{* * *}$ \\
& $(0.135)$ & $(0.101)$ \\
per & $-0.807^{* * *}$ & $-0.810^{* * *}$ \\
& $(0.027)$ & $(0.026)$ \\
awar & $-8.875^{* * *}$ & $-9.110^{* * *}$ \\
& $(1.434)$ & $(1.244)$ \\
amb & 0.478 & \\
& $(1.455)$ & \\
awar·sure & $0.446^{* *}$ & $0.476^{* * *}$ \\
& $(0.189)$ & $(0.167)$ \\
amb·sure & $-0.655^{* * *}$ & $-0.596^{* * *}$ \\
& $(0.192)$ & $(0.061)$ \\
awar·per & $0.487^{* * *}$ & $0.489^{* * *}$ \\
& $(0.038)$ & $(0.037)$ \\
amb·per & $0.243^{* * *}$ & $0.248^{* * *}$ \\
& $(0.038)$ & $(0.036)$ \\
const & $18.216^{* * *}$ & $18.450^{* * *}$ \\
& $(1.019)$ & $(0.727)$ \\
$N$ & 310 & 310 \\
\hline \hline
\end{tabular}

Table 5: Random effects regression of response times in the first 16 periods of the Risk, Ambiguity and Unawareness treatments. 


\subsection{Patterns in Average Behavior}

We finally analyze the patterns in average behavior across treatments. We construct the variable absc. For each participant $i$ for periods 1 to 16

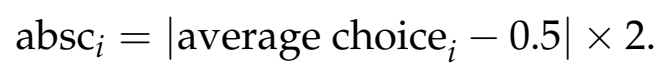

absc ranges from 0 to 1 . Participants with absc $=0$ choose the sure outcome and the lottery an equal number of times. Participants with absc=1 choose only the sure outcome or only the lottery. Thus, absc shows how often participants switch between the alternatives.

Figure 6 shows the distributions of absc for the three treatments in periods 1 to 16 . One can see that on average in Unawareness treatment participants tend to switch a lot between the lottery and sure outcome whereas in the Ambiguity treatment participants stick more often to the same alternative.

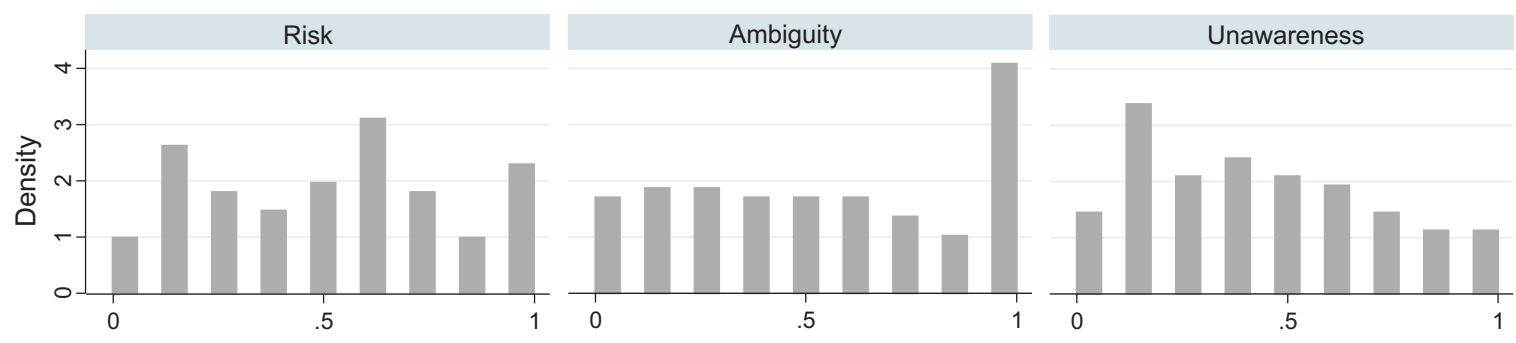

Figure 6: Histograms of absc by treatment in periods 1 to 16.

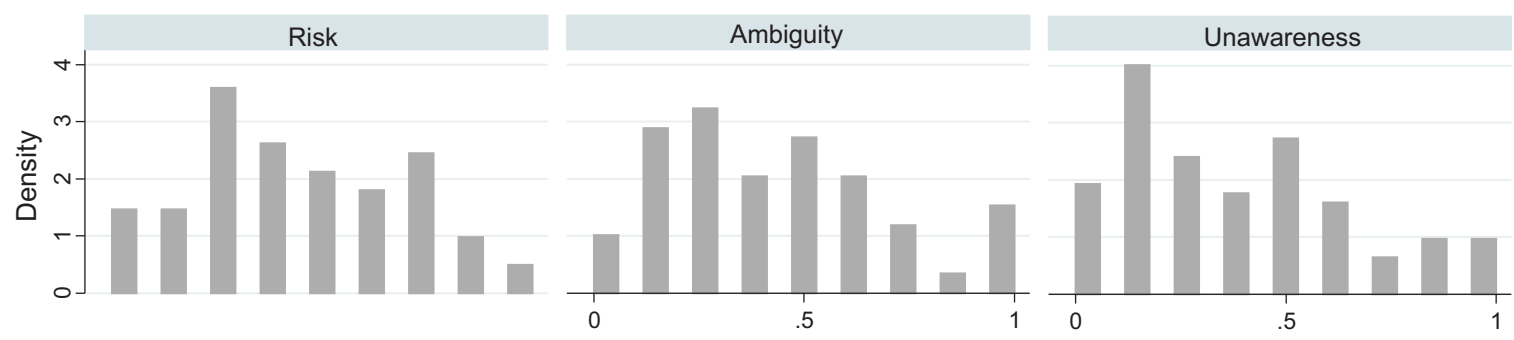

Figure 7: Histograms of absc by treatment in periods 17 to 32.

Mann Whitney tests show significant difference in the distributions of absc between Risk and Unawareness $(p<0.041)$ and between Ambiguity and Unawareness $(p<0.017)$ but no significant difference between Risk and Ambiguity $(p>0.542)$. This again confirms our hypothesis that choice process in Ambiguity and Risk treatments is different from Unawareness treatment.

The difference between distributions is only observed in the first 16 periods but not in the periods 17 to 32 . All distributions on Figure 7 look the same with the peak 
in the middle and no significance in the Mann-Whitney tests $(p>0.0677, p>0.1447$ and $p>0.6464$ respectively). This shows that in periods 17 to 32 participants do react to the choices in a similar way since they observe full information about the lotteries. The only difference is a shift in the risk attitudes.

Result 2 1. Participants in Unawareness treatment are less likely to choose the lottery and display longer response times in the periods immediately following "surprise".

2. In Unawareness treatment they are less likely to choose the lottery in periods 1 to 16 and react less to the value of the sure outcome compared to either Risk or Ambiguity treatment which are not significantly different.

3. Response times are overall faster in Unawareness treatment compared to Risk and Ambiguity treatments. They are faster the higher the value of the sure outcome in both Risk and Ambiguity treatments, but do not vary with the value of the sure outcome in the Unawareness treatment.

\section{Discussion}

In this section we discuss some possible explanations for the lasting effects of past exposure to Risk, Ambiguity and Unawareness. It seems intuitive that experiencing more (and unusually high) uncertainty makes people focus more on uncertainty (as represented by the standard deviation of a lottery) in future decision processes.

In fact several studies in psychology suggest that emotional states influence the perception of risk. For example, it was found that affect (Johnson and Tversky, 1983), fear (Lerner and Keltner, 2001) and anxiety (Raghunathan and Pham, 1999) make people more risk averse in the future. Functional Magnetic Resonance Imaging studies point at specific regions in the human brain, for example amygdala, that are activated in these emotional states (see e.g. the meta-study by Phan et al., 2002). We hypothesize that experiencing different levels of surprise trigger some of these emotional responses. Moreover, surprise in the Unawareness treatment seems to be very salient. Evidence of this is provided in Section 5.

There is also some relation of this work to a literature on behavioural spillovers (see e.g. Gneezy, Rustichini, and Vostroknutov, 2010; Haruvy and Stahl, 2009; Mengel and Sciubba, 2010). These authors show that cognitive skills (such as applying backward induction or iterated elimination of dominates strategies) can be extrapolated across games. It is hard to argue that the spillover effects in our experiment 
have much to do with transfer of cognitive skills or learning. In fact we conducted a control treatment, where participants only faced the lotteries from periods 17 to 32 . Behaviour in this treatment is not significantly different from behaviour in the risk treatment. ${ }^{14}$ There is also no evidence in our study that participants would use different heuristics in periods 17 to 32 across the different treatments. Instead it seems that their attention is shifted towards giving greater weight to the uncertainty of a choice option. This supports the view that preferences can be endogenous to the decision situation and can be shaped by previous experiences and/or a process of cultural transmission of norms and ideas. It is also consistent with the "risk-as-feelings" hypothesis outlined above and supported e.g. by Loewenstein et al. (2001).

\footnotetext{
${ }^{14}$ We redid the main regression reported in Table 2 using again Risk treatment as a baseline and found the following coefficients together with significance levels: dexp $1.117^{* * *}$, stdv $-0.300^{* * *}$, control -0.200 , control.stdv -0.068 , const $0.819^{* * *}$.
} 


\section{Appendix}

\subsection{Details of the Design}

Table 6 shows the sequence of lotteries and sure outcomes observed by the participants in periods 17 to 32 .

\begin{tabular}{lllllllll}
\hline Choice & \multicolumn{4}{c}{ Lottery } & \multicolumn{4}{c}{ Sure Outcomes } \\
& & & & \multicolumn{5}{c}{ Cohort } \\
& $x_{1}$ & $x_{2}$ & $p_{1}$ & $p_{2}$ & 1 & 2 & 3 & 4 \\
\hline 17 & 4 & 14 & 0.6 & 0.4 & 7.0 & 7.5 & 6.0 & 6.5 \\
18 & 4 & 10 & 0.33 & 0.67 & 6.5 & 7.5 & 7.0 & 6.0 \\
19 & 5 & 17 & 0.75 & 0.25 & 7.5 & 6.5 & 8.0 & 7.0 \\
20 & 2 & 15 & 0.54 & 0.46 & 6.0 & 7.0 & 7.5 & 6.5 \\
21 & 5 & 9 & 0.25 & 0.75 & 7.5 & 8.0 & 6.5 & 7.0 \\
22 & 3 & 9 & 0.17 & 0.83 & 8.0 & 7.0 & 6.5 & 7.5 \\
23 & 2 & 20 & 0.67 & 0.33 & 6.5 & 7.5 & 7.0 & 8.0 \\
24 & 5 & 19 & 0.79 & 0.21 & 7.0 & 6.0 & 6.5 & 7.5 \\
25 & 3 & 14 & 0.55 & 0.45 & 6.5 & 8.0 & 7.5 & 7.0 \\
26 & 4 & 11 & 0.43 & 0.57 & 6.5 & 7.0 & 8.0 & 7.5 \\
27 & 4 & 12 & 0.5 & 0.5 & 7.0 & 6.5 & 7.5 & 8.0 \\
28 & 2 & 13 & 0.45 & 0.55 & 8.0 & 6.5 & 7.0 & 7.5 \\
29 & 3 & 11 & 0.38 & 0.62 & 6.0 & 7.0 & 7.5 & 6.5 \\
30 & 3 & 15 & 0.58 & 0.42 & 7.5 & 6.0 & 6.5 & 7.0 \\
31 & 2 & 10 & 0.25 & 0.75 & 7.0 & 7.5 & 6.0 & 6.5 \\
32 & 5 & 12 & 0.57 & 0.43 & 7.5 & 6.5 & 7.0 & 6.0 \\
\hline
\end{tabular}

Table 6: Choices 17 to 32.

Participants were divided into 4 cohorts. In each choice each cohort faced the same lottery but different sure outcome. The participants were divided into 4 cohorts in order to create vmore variability in the data. 


\subsection{Definitions of Variables}

\begin{tabular}{|c|c|}
\hline Variable & Definition \\
\hline per & $\begin{array}{l}\text { Choice period. Ranges from } 1 \text { to } 16 \text { for the first } 16 \text { periods and } 1 \\
\text { to } 16 \text { for the last } 16 \text { periods (first and last } 16 \text { periods are always } \\
\text { analyzed separately) }\end{array}$ \\
\hline choice & $0 / 1$ variable. Is 1 if the lottery was chosen \\
\hline resptime & Time in seconds it took participant to choose \\
\hline awar & $0 / 1$ variable. Is 1 if the choice is made in the Unawareness treatment \\
\hline$a m b$ & $0 / 1$ variable. Is 1 if the choice is made in the Ambiguity treatment \\
\hline$x_{1}, x_{2}$ & For the last 16 periods: outcomes of the lottery \\
\hline$p_{1}, p_{2}$ & For the last 16 periods: probabilities of the outcomes of the lottery \\
\hline sure & $\begin{array}{l}\text { The sure outcome. For the first } 16 \text { periods ranges in }[5.4,8.4] \text {, mean } \\
6.9\end{array}$ \\
\hline $\operatorname{dexp}$ & $\begin{array}{l}\text { For the last } 16 \text { periods: expected value of the lottery minus sure } \\
\text { outcome }=\left(p_{1} x_{1}+p_{2} x_{2}\right)-\text { sure. } \\
\text { Ranges in }[-0.06,2.04] \text {, mean } 0.99\end{array}$ \\
\hline$s t d v$ & $\begin{array}{l}\text { For the last } 16 \text { periods: square root of the variance of the lottery. } \\
\text { Ranges in }[1.73,8.46] \text {, mean } 4.54\end{array}$ \\
\hline firstsp & $\begin{array}{l}0 / 1 \text { variable. For periods } 1 \text { to } 16 \text { in Unawareness treatment: is equal } \\
\text { to } 1 \text { in all periods including and after the one in which participant } \\
\text { saw first previously unknown outcome }(-1 \text {, Twix, or }-20)\end{array}$ \\
\hline
\end{tabular}




\subsection{Instructions}

\subsubsection{Risk Treatment}

\section{General Explanations for Participants}

You are participating in a choice experiment that is financed by the Marie Curie grant. You will receive 4 Euro for your participation. You can earn additional money with the decisions you make. Your earnings may also depend on random events. The exact way your earnings are calculated is explained in this document and during the experiment. It is, therefore, very important that you carefully read the following explanations. At the end of the experiment you will be instantly and confidentially paid in cash all the money you have earned.

During the experiment you are not allowed to communicate. If you have any questions please raise your hand. An experimenter will come to answer your questions.

\section{Information on the Exact Procedure of the Experiment}

The experiment consists of a main part and a questionnaire. The main part consists of a sequence of 32 periods. In the questionnaire we will ask you to provide some general information about yourself. In each period in the main part of the experiment you will have a chance to earn money. At the end of the experiment you will be paid for one period only that will be determined randomly.

\section{Instructions for the Main Part of the Experiment}

\section{Typical Choice}

The main part of the experiment consists of 32 different periods. In each period you can choose between a lottery and a sure outcome. Here is an example of one period:

\begin{tabular}{llllc}
\hline Outcomes (Euro) & & & & \\
& 2 & 5 & 7 & Sure Outcome (Euro) \\
& 0.2 & 0.5 & 0.3 & 4.5 \\
Probabilities & & & & \\
\hline
\end{tabular}

In this example, if you choose sure outcome then in case this period is selected for your payment you will receive 4.5 Euro in addition to the 4 Euro you receive for your participation. If you choose the lottery then you might receive 2 Euro, 5 Euro, or 7 Euro (also in addition to the 4 Euro you receive for your participation). Each of these three possible outcomes can happen with the probabilities described below each number. For example here there is a $20 \%$ chance that you receive 2 Euro; a 50\% chance that you receive 5 Euro; and a 30\% chance that you receive 7 Euro. In case you choose the lottery you will be informed after your choice about which outcome of the lottery has occurred.

Also keep in mind that irrespective of whether you choose the sure outcome or the lottery you receive this amount of money only if this period is selected for your payment. 


\section{Non-Monetary Outcomes}

The outcomes of the lottery might also be represented by the objects other than monetary outcomes. For example, you might have a Twix candy as one of the outcomes of the lottery. If this is the case, instead of the monetary amount you will see a picture like this:

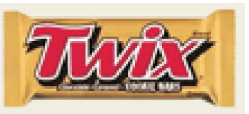

In case you choose a lottery, Twix occurs as the outcome and the period in which you received Twix is randomly selected for your payment you will receive the candy from the experimenters in the end of the experiment (plus the show up payment). 


\subsubsection{Ambiguity Treatment}

\section{General Explanations for Participants}

You are participating in a choice experiment that is financed by the Marie Curie grant. You will receive 4 Euro for your participation. You can earn additional money with the decisions you make. Your earnings may also depend on random events. The exact way your earnings are calculated is explained in this document and during the experiment. It is, therefore, very important that you carefully read the following explanations. At the end of the experiment you will be instantly and confidentially paid in cash all the money you have earned.

During the experiment you are not allowed to communicate. If you have any questions please raise your hand. An experimenter will come to answer your questions.

\section{Information on the Exact Procedure of the Experiment}

The experiment consists of a main part and a questionnaire. The main part consists of a sequence of 32 periods. In the questionnaire we will ask you to provide some general information about yourself. In each period in the main part of the experiment you will have a chance to earn money. At the end of the experiment you will be paid for one period only that will be determined randomly.

\section{Instructions for the Main Part of the Experiment}

\section{Typical Choice}

The main part of the experiment consists of 32 different periods. In each period you can choose between a lottery and a sure outcome. Here is an example of one period:

\begin{tabular}{llllc}
\hline Outcomes (Euro) & & & & \\
& 2 & 5 & 7 & Sure Outcome (Euro) \\
& 0.2 & 0.5 & 0.3 & 4.5 \\
Probabilities & & & & \\
\hline
\end{tabular}

In this example, if you choose sure outcome then in case this period is selected for your payment you will receive 4.5 Euro in addition to the 4 Euro you receive for your participation. If you choose the lottery then you might receive 2 Euro, 5 Euro, or 7 Euro (also in addition to the 4 Euro you receive for your participation). Each of these three possible outcomes can happen with the probabilities described below each number. For example here there is a $20 \%$ chance that you receive 2 Euro; a 50\% chance that you receive 5 Euro; and a 30\% chance that you receive 7 Euro. In case you choose the lottery you will be informed after your choice about which outcome of the lottery has occurred.

Also keep in mind that irrespective of whether you choose the sure outcome or the lottery you receive this amount of money only if this period is selected for your payment. 


\section{Non-Monetary Outcomes}

The outcomes of the lottery might also be represented by the objects other than monetary outcomes. For example, you might have a Twix candy as one of the outcomes of the lottery. If this is the case, instead of the monetary amount you will see a picture like this:

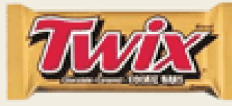

In case you choose a lottery, Twix occurs as the outcome and the period in which you received Twix is randomly selected for your payment you will receive the candy from the experimenters in the end of the experiment (plus the show up payment).

\section{Hidden Information}

It is also possible that you will not observe all the information about the lottery. For example you might see a choice represented like this:

\begin{tabular}{lllllc}
\hline Outcomes (Euro) & & & & \\
& 2 & 5 & 7 & Sure Outcome (Euro) \\
& & & & 4.5 \\
Probabilities & & & & \\
\hline
\end{tabular}

Here you are still choosing between a sure outcome and some fixed lottery (for example, this could be the exact same lottery as in the previous example above). The only difference is that you do not know the probabilities with which the outcomes of the lottery occur. In case you choose the lottery you will observe the realized outcome immediately.

IMPORTANT NOTE: in ALL periods in which you do not observe the probabilities of the lottery outcomes, the actual lottery is EXACTLY THE SAME, both in terms of the outcomes and the unobserved probabilities. 


\subsubsection{Unawareness Treatment}

\section{General Explanations for Participants}

You are participating in a choice experiment that is financed by the Marie Curie grant. You will receive 4 Euro for your participation. You can earn additional money with the decisions you make. Your earnings may also depend on random events. The exact way your earnings are calculated is explained in this document and during the experiment. It is, therefore, very important that you carefully read the following explanations. At the end of the experiment you will be instantly and confidentially paid in cash all the money you have earned.

During the experiment you are not allowed to communicate. If you have any questions please raise your hand. An experimenter will come to answer your questions.

\section{Information on the Exact Procedure of the Experiment}

The experiment consists of a main part and a questionnaire. The main part consists of a sequence of 32 periods. In the questionnaire we will ask you to provide some general information about yourself. In each period in the main part of the experiment you will have a chance to earn money. At the end of the experiment you will be paid for one period only that will be determined randomly.

\section{Instructions for the Main Part of the Experiment}

\section{Typical Choice}

The main part of the experiment consists of 32 different periods. In each period you can choose between a lottery and a sure outcome. Here is an example of one period:

\begin{tabular}{lllll}
\hline Outcomes (Euro) & & & & \\
& 2 & 5 & 7 & Sure Outcome (Euro) \\
& 0.2 & 0.5 & 0.3 & 4.5 \\
Probabilities & & & & \\
\hline
\end{tabular}

In this example, if you choose sure outcome then in case this period is selected for your payment you will receive 4.5 Euro in addition to the 4 Euro you receive for your participation. If you choose the lottery then you might receive 2 Euro, 5 Euro, or 7 Euro (also in addition to the 4 Euro you receive for your participation). Each of these three possible outcomes can happen with the probabilities described below each number. For example here there is a $20 \%$ chance that you receive 2 Euro; a 50\% chance that you receive 5 Euro; and a 30\% chance that you receive 7 Euro. In case you choose the lottery you will be informed after your choice about which outcome of the lottery has occurred.

Also keep in mind that irrespective of whether you choose the sure outcome or the lottery you receive this amount of money only if this period is selected for your payment. 


\section{Hidden Information}

It is also possible that you will not observe all the information about the lottery. For example you might see a choice represented like this:

\begin{tabular}{llcc}
\hline Outcomes (Euro) & & \\
& 2 & 5 & Sure Outcome (Euro) \\
Probabilities & & 4.5 \\
\hline
\end{tabular}

Here you are still choosing between a sure outcome and some fixed lottery (for example, this could be the exact same lottery as in the previous example above). The only difference is that you do not know the probabilities with which the outcomes of the lottery occur. It may also be the case that you do not know some of the outcomes. For example, if the lottery here is the same as in the example on the previous page, you do not know that the outcome 7 Euro can occur. Note that outcomes can occur also if you don't observe them. If you choose the lottery and the previously unobserved outcome 7 Euro occurs, then you will observe it as a possibility afterwards:

\begin{tabular}{lllllc}
\hline Outcomes (Euro) & & & & \\
& 2 & 5 & 7 & Sure Outcome (Euro) \\
& & & & 6.5 \\
Probabilities & & & \\
\hline
\end{tabular}

Not all the lotteries you are about to see will have hidden information. For some lotteries you will observe the probabilities of the outcomes. To check that there are no hidden outcomes you may sum up the probabilities and verify that they add up to 1.

IMPORTANT NOTE: in ALL periods in which you do NOT observe the probabilities and/or the outcomes, the actual lottery is EXACTLY THE SAME, both in terms of the outcomes and the unobserved probabilities. In addition, some unobserved outcomes will be revealed to you over time. When this happens you will observe them on your screen. 


\section{References}

Ahn, D., S. ChOI, D. Gale, AND S. Kariv (2010): “Estimating Ambiguity Aversion in a Portfolio Choice Experiment," UC Berkeley, UCL, NYU and UC Berkeley.

Anscombe, F., And R. Aumann (1963): "A Definition of Subjective Probability," Annals of Mathematical Statistics, 34(1), 199-205.

BogACZ, R. (2007): “Optimal decision-making theories: linking neurobiology with behaviour," Trends in Cognitive Sciences, 11(3), 118-125.

DeKel, E., B. Lipman, AND A. Rustichini (1998): “Standard State-Space Models Preclude Unawareness," Econometrica, 66(1), 159-173.

EllsberG, D. (1961): "Risk, Ambiguity, and the Savage Axioms," Quarterly Journal of Economics, 75(4), 643-669.

FAGIN, R., AND J. HALPERN (1988): “Belief, awareness, and limited reasoning," Artificial Intelligence, 34, 39-76.

FEINBERG, Y. (2009): “Games with Unawareness," Stanford University.

FisCHBACHER, U. (2007): “z-Tree: Zurich Toolbox for Ready-made Economic Experiments," Experimental Economics, 10(2), 171-178.

GIUlianO, P., AND A. SPILIMBERGO (2009): “Growing up in a recession: beliefs and the macroeconomy," UCLA, NBER, IZA, IMF, WDI and CEPR.

Gneezy, U., A. Rustichini, And A. Vostroknutov (2010): “Experience and insight in the Race game," Journal of Economic Behavior and Organization, 75, 144-155.

Gollier, C. (2009): "Portfolio choices and asset prices: The comparative statics of ambiguity aversion," Toulouse School of Economics (LERNA and IDEI).

Halevy, Y. (2007): “Ellsberg Revisited: An Experimental Study," Econometrica, 75, 503-536.

HALPERN, J. Y., AND L. C. RÊGO (2008): "Interactive unawareness revisited," Games and Economic Behavior, 62(1), 232-262.

HARUVY, E., AND D. O. STAHL (2009): "Learning Transference Between Dissimilar Symmetric Normal-Form Games," mimeo, University of Texas at Dallas and University of Texas at Austin.

Heifetz, A., M. Meier, AND B. C. SChipper (2006): "Interactive unawareness," Journal of Economic Theory, 130, 78-94.

Johnson, E. J., AND A. TVERSKY (1983): “Affect, Generalization, and the Perception of Risk," Journal of Personality and Social Psychology, 45(1), 20-31. 
KNIGHT, F. (1921): Risk, uncertainty and profit. Boston: Houghton Mifflin.

LERNER, J. S., AND D. KeltneR (2001): "Fear, Anger, and Risk," Journal of Personality and Social Psychology, 81(1), 146-159.

LI, J. (2009): "Information structures with unawareness," Journal of Economic Theory, 144, 977-993.

Loewenstein, G. F., E. U. Weber, C. K. Hsee, and N. Welch (2001): "Risk as Feelings," Psychological Bulletin, 127(2), 267-286.

Maccheroni, F., M. Marinacci, And A. Rustichini (2006): “Ambiguity Aversion, Robustness, and the Variational Representation of Preferences," Econometrica, 74(6), 1447-1498.

MALMEndieR, U., AND S. NAGEL (2010): "Depression babies: do macroeconomic experiences affect risk taking?," Quarterly Journal of Economics, forthcoming.

MARKOWITZ, H. (1952): “Portfolio Selection," Journal of Finance, 7(1), 77-91.

McFadden, D. (1976): “Quantal Choice Analysis: A Survey," Annals of Economics and Social Measurement, 5, 363-390.

MENGEL, F., AND E. SCIUBBA (2010): "Extrapolation and structural learning in games," Maastricht University and Birkbeck College London.

ModicA, S., AND A. Rustichini (1994): “Awareness and partitional information structures," Theory and Decision, 37(1), 107-124.

(1999): "Unawareness and Partitional Information Structures," Games and Economic Behavior, 27, 265-298.

NishiYAMA, Y. (2006): "The Asian Financial Crisis and Investors' Risk Aversion," Asia-Pacific Financial Markets, 13, 181-205.

O'Doherty, J. P., P. DAyAn, K. Friston, H. CRitchley, and R. J. Dolan (2003): "Temporal Difference Models and Reward-Related Learning in the Human Brain," Neuron, 28, 329337.

Osili, U. O., AND A. PAulson (2009): "Banking crises and Investor Confidence: An Empirical Investigation," Indiana University-Purdue University at Indianapolis and Federal Reserve Bank of Chicago.

PhAN, K. L., T. WAGER, S. F. TAYlOR, AND I. LibERZON (2002): “Functional Neuroanatomy of Emotion: A Meta-Analysis of Emotion Activation Studies in PET and fMRI," Neuroimage, 16(2), 331348.

Preuschoff, K., P. Bossaerts, And S. R. QuARTZ (2006): “Neural Differentiation of Expected Reward and Risk in Human Subcortical Structures," Neuron, 51(3), 381-390. 
Raghunathan, R., And M. T. Pham (1999): “All Negative Moods Are Not Equal: Motivational Influences of Anxiety and Sadness on Decision Making," Organizational Behavior and Human Decision Processes, 79(1), 5677.

SAVAGE, L. (1954): The foundations of Statistics. New York: Wiley. 